Article

\title{
Parametric Studies for Combined Convective and Conductive Heat Transfer for YASA Axial Flux Permanent Magnet Synchronous Machines
}

\author{
Abdalla Hussein Mohamed ${ }^{1,2,3, *}$, Ahmed Hemeida ${ }^{3,4}$, Hendrik Vansompel ${ }^{1,2}$ \\ and Peter Sergeant ${ }^{1,2} \mathbb{D}$ \\ 1 Department of Electrical Machines, Metals, Mechanical Constructions and Systems, Ghent University, \\ 9052 Ghent, Belgium; hendrik.vansompel@UGent.be (H.V.); peter.sergeant@UGent.be (P.S.) \\ 2 EEDT, Flanders Make, The Research Centre for the Manufacturing Industry, B-8500 Kortrijk, Belgium \\ 3 Department of Electrical Power and Machines, Cairo University, Giza 12613, Egypt; a.hemeida@live.com \\ 4 Department of Electrical Engineering and Automation, Aalto University, P.O. Box 13000, \\ FI-00076 Espoo, Finland \\ * Correspondence: a.hussien.rashad@gmail.com; Tel.: +3-246-582-7320
}

Received: 12 October 2018; Accepted: 28 October 2018; Published: 1 November 2018

\begin{abstract}
In this paper, the effect of some geometrical parameters on the steady state average temperature of the stator core, the winding and the permanent magnets of the yokeless and segmented armature (YASA) axial flux permanent magnet synchronous machine (AFPMSM) is studied. The geometrical parameters selected for the study are the air gap length, the inward heat extraction fin thickness and the permanent magnet thickness. These parametric studies make it possible to obtain a better trade-off between power density and efficiency. These investigations are very helpful in correlating the values of the geometrical parameters to some specific desired performance criteria like not going below some desired minimum efficiency, limiting the temperature of specific part to some maximum value for maximization of lifetime and also determination of the allowed speed range to limit the temperatures lower than the critical values. This is important specifically for the synchronous machines due to the fact that the speed value affects both the losses and the heat transfer convection coefficients. The air gap length has a direct effect on the overall machine losses and the air gap convection coefficient and hence on the temperature of the machine. As the fins are between the stator windings, a thicker fin reduces the space for copper windings and hence increases the losses, but at the same time improves heat evacuation. In addition, the effect on the temperature is studied of the speed variation, which influences both the losses and the convection coefficients of the machine. Every study is made based on coupled electromagnetic and thermal models. The results are obtained from analytical electromagnetic and thermal models verified by finite element simulations and validated experimentally on a $4 \mathrm{~kW}$ yokeless and segmented armature axial flux machine.
\end{abstract}

Keywords: YASA; AFPMSM; electromagnetic model; thermal model; parametric study

\section{Introduction}

Many types of axial flux permanent magnet synchronous machines exist. These types differ in the number of stators and rotors and the location of them in the machine. Some of these types are axial flux internal rotor (AFIR), toroidally wound internal stator (TORUS), axial flux internal stator (AFIS) and yokeless and segmented armature (YASA) [1]. The absence of the stator yoke in the YASA type makes it more efficient. The complete design and optimization of the YASA machine needs accurate electromagnetic, thermal and mechanical models for the machine. The electromagnetic 
models are mainly providing the magnetic field distribution in the machine parts. Based on the calculated magnetic field distribution, many important quantities can be calculated. The developed torque, the cogging torque, the induced voltage, the permanent magnets losses and the core losses are some of these quantities [2]. Two main methods for the electromagnetic modeling exist: the finite element method (FEM) and the analytical method. The 3D FEM modeling method is the most accurate and the most time-consuming one [3-5]. Another quasi-3D FEM method is used in which the machine is divided into slices in the radial direction, the flux density distribution is calculated for every slice and then summation is done to obtain the total flux. This method provides a good compromise between the accuracy and the solution time [2,6]. The magnetic equivalent circuit (MEC), the analytical solutions of Maxwell's equations and the combination of them are the analytical electromagnetic modeling methods [7-9].

For thermal modeling, the FEM and the lumped parameter thermal network method (LPTN) represent the numerical and the analytical thermal modeling methods. Refs. [10-13] are some of the papers presenting the FEM thermal modeling technique for the YASA machine while [14-16] studied the LPTN modeling method. The LPTN method has the advantage of being fast enough while, on the other hand, the FEM method provides a more detailed temperature distribution in every part. In this paper, the effect of the air gap length, the speed, the heat extraction fins thickness and the permanent magnet (PM) thickness on the machine losses and the temperature is studied. The coupling between the electromagnetic model and the thermal model is necessary for the studies in this paper for two reasons. The first one is the dependence of the machine losses on the values of the studied parameters and the second one is the temperature dependent material properties [17].

\section{YASA Electromagnetic Models}

The electromagnetic model must be able to accurately compute several loss terms as a function of the studied parameters: winding loss, the iron loss, and the loss in the permanent magnets. These losses are the sources of the thermal model in Section 3.

The analytical electromagnetic model (EM) adopted for parametric studies in this paper is the quasi-3D modeling technique combined with the magnetic equivalent circuit [2].

The core losses are calculated using the method of loss separation (1) [18]:

$$
\begin{aligned}
& P_{\text {loss }}=\left(P_{\text {hys }}+P_{\text {classic }}+P_{\text {excess }}\right) \rho, \\
& P_{\text {hys }}=K_{1} B_{p}{ }^{k_{2}} f, \\
& P_{\text {class }}(t)=K_{3}\left(\frac{d B}{d t}\right)^{2}, \\
& P_{\text {excess }}(t)=K_{4}\left(\sqrt{1+k_{5}\left|\frac{d B}{d t}\right|}-1\right) \frac{d B}{d t},
\end{aligned}
$$

where $P_{\text {loss }}$ is the power loss $\mathrm{W} / \mathrm{m}^{3}, P_{\text {hys }}$ is the hysteresis losses, $P_{\text {classic }}$ is the classic loss, $P_{\text {excess }}$ is the excess loss, $\rho$ is the mass density, $\left(K_{1}-K_{5}\right)$ are material dependent constants, and $f$ is the frequency $B_{p}$ is the peak flux density.

For the PM losses, the method developed in [6] is adopted here.

The dependency of the core and PM losses on the frequency is clear. Remaining is the dependency of the winding losses on the frequency which comes from the skin and proximity effects. The AC resistance $R_{A C}$ can be calculated from (2) [19]: 


$$
\begin{aligned}
& t_{d}=\frac{1}{\sqrt{\pi f \mu_{0} \sigma}}, \\
& K_{r}=\frac{d_{c}}{t_{d}}, \\
& G_{b}=K_{r} \frac{\sinh 2 K_{r}+\sin 2 K_{r}}{\cosh 2 K_{r}-\cos 2 K_{r}}, \\
& G_{b r}=2 K_{r} \frac{\sinh K_{r}-\sin K_{r}}{\cosh K_{r}+\cos K_{r}}, \\
& K_{i n}=G_{b}+\frac{m^{2}-1}{3 G_{b r}}, \\
& R_{A C}=K_{i n} \times R_{D C},
\end{aligned}
$$

where $f$ is the frequency in $\mathrm{Hz}, \sigma$ is the conductor conductivity in $\mathrm{S} / \mathrm{m}, t_{d}$ is the skin depth in meters, $d_{c}$ is the conductor diameter, $m$ is the number of conductors along the axial length of the slot, $K_{r}$ is the ratio between the actual conductor diameter and the effective conductor diameter seen by the AC current flowing, $K_{\text {in }}$ is the ration between the AC and the DC resistances of the same conductor at certain frequency and $R_{D C}$ is the conductor resistance seen by a zero frequency current.

\section{YASA Thermal Models}

In this section, the analytical thermal model adopted for the coupling studies in this paper is discussed along with the FEM thermal model used to verify the results of the coupled models based studies in the next sections.

\subsection{YASA LPTN}

The lumped parameter thermal network (LPTN) is a network of thermal resistors, capacitors and heat sources. The solution of the network gives the average temperature of each element represented by a node in this network. The values of these resistors and capacitors are driven from the material properties and geometry of the machine under study. The geometry of the YASA machine under study is shown in Figure 1, while the material properties are given in Table 1.

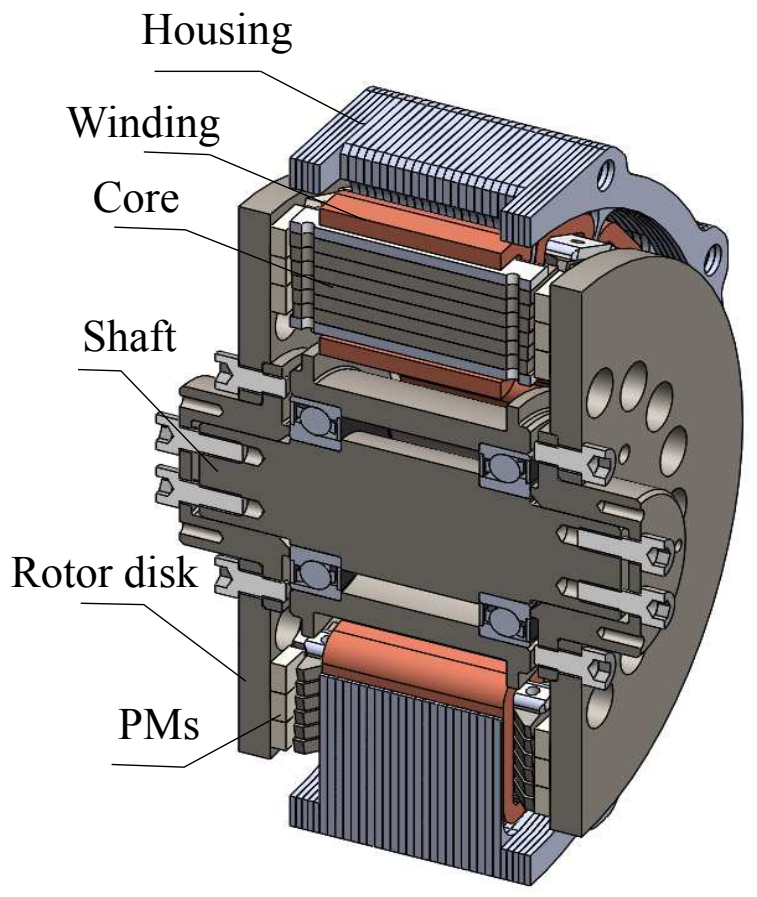

Figure 1. Cross-section view of the YASA prototype. 
Table 1. Material properties.

\begin{tabular}{lccr}
\hline Material & $K(\mathrm{~W} / \mathrm{mK})$ & $C_{p}(\mathrm{~J} / \mathbf{k g K})$ & $\rho\left(\mathrm{kg} / \mathrm{m}^{3}\right)$ \\
\hline copper & 385 & 392 & 8890 \\
aluminum & 167 & 896 & 2712 \\
epoxy & 0.4 & 600 & 1540 \\
nylon & 0.25 & 1600 & 1140 \\
Nd-Fe-B & 9 & 500 & 7500 \\
\hline
\end{tabular}

The details of the LPTN model developed by the authors and adopted for the study in this paper can be found in [16]. In this model, the rotor and the stator are represented by two different networks coupled by the analytical convection heat transfer coefficients in $[20,21]$. The analytical equations for the convection coefficients calculation take the form (3).

$$
\begin{gathered}
G=\frac{2 g}{D}, \\
R e=\frac{\Omega D^{2}}{4 v}, \\
\alpha_{m}=\alpha \times \frac{N_{m}}{360}, \\
L=\frac{t}{R} \\
N \bar{u}_{h_{i}}=Y_{h_{i}}\left(G, R e, \alpha_{m}, L\right), \\
\overline{h_{i}}=\frac{N u_{i} k}{l_{i}},
\end{gathered}
$$

where $g$ is the air gap length in $\mathrm{m}, D$ is the rotor disk diameter in $\mathrm{m}, \Omega$ is the rotational speed in rad/s, $v$ is the kinematic viscosity of the air, $\alpha$ is the magnet angle, $t$ is the magnet thickness, $R$ is the rotor radius, $\overline{h_{i}}$ is the convection coefficient of the surface $i, K$ is the air thermal conductivity and $l_{i}$ is the characteristic length of the air.

It is important to notice from equation (3) that the convection coefficients depend on the air gap length, rotational speed and the magnets' geometrical parameters. This means that the change of these parameters, besides affecting the machine losses, also affects the convection coefficients. This makes the study of the variation of these parameters on the machine temperature very interesting and useful in the selection of these parameters.

The LPTN for the stator and the rotor is shown in Figures 2 and 3, respectively.

The $T_{r e f}$ indicated in the LPTN represents the temperature of a nearby volume of air close to the convected surface $[20,21]$. The value of this temperature depends on the average temperature of the stator $T_{s}$ and the rotor $T_{r}$ and also on the same parameters as the convection coefficients (4):

$$
\begin{aligned}
& a_{h i}=F_{h i}\left(G, R e, \alpha_{m}, L\right), \\
& b_{h i}=G_{h i}\left(G, R e, \alpha_{m}, L\right), \\
& \bar{T}_{r e f_{i}}=a_{i} T_{r}+b_{i} T_{s}+\left(1-\left(a_{i}+b_{i}\right)\right) T_{a},
\end{aligned}
$$

where $T_{a}$ is the ambient temperature.

It is important to mention here that, due to symmetry and thermal periodicity, only one-quarter of one of the stator teeth is modeled and only one rotor PM. The LPTNs of the stator and the rotor are then solved to get the temperature of the machine. 


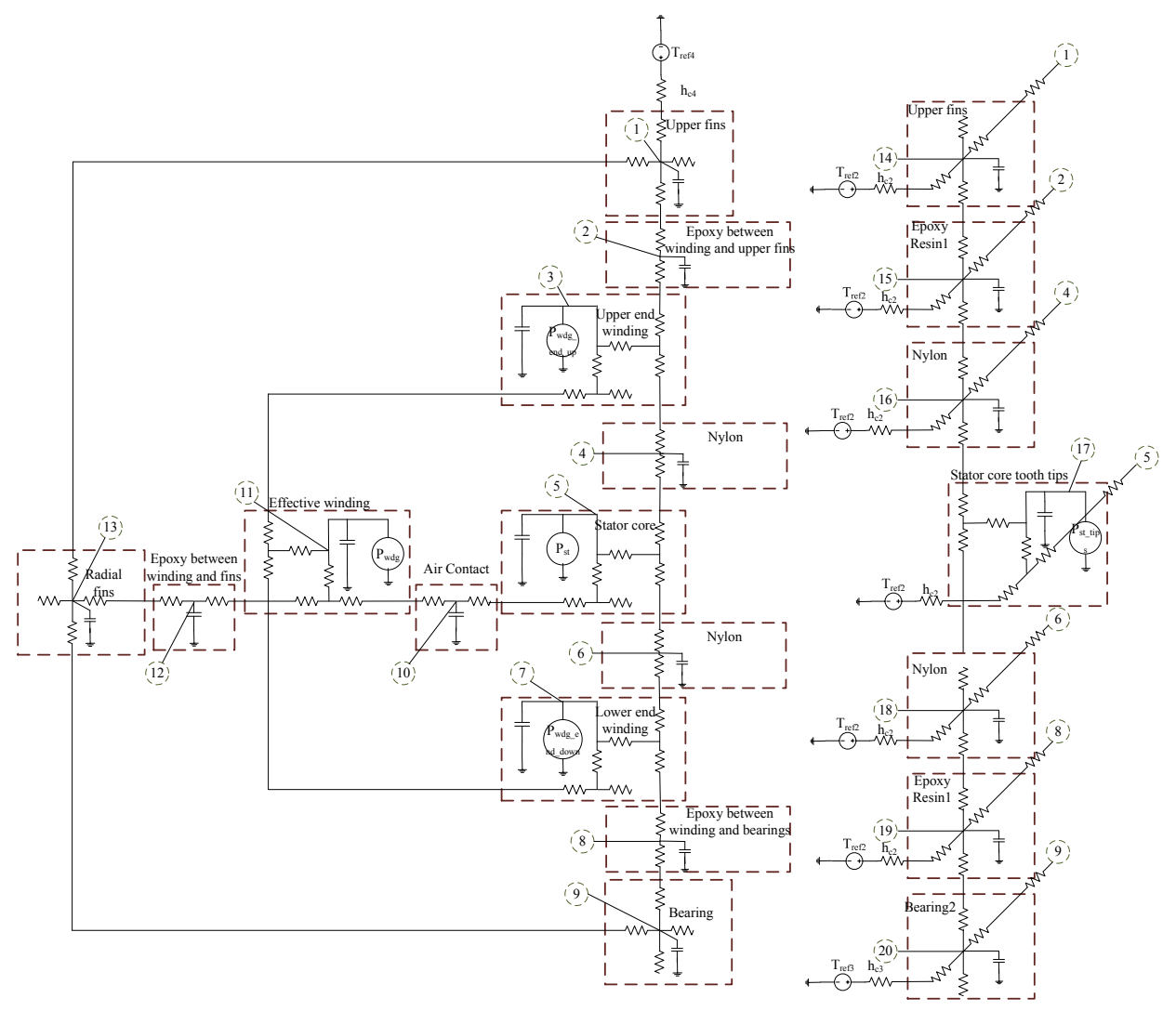

Figure 2. LPTN of the stator.

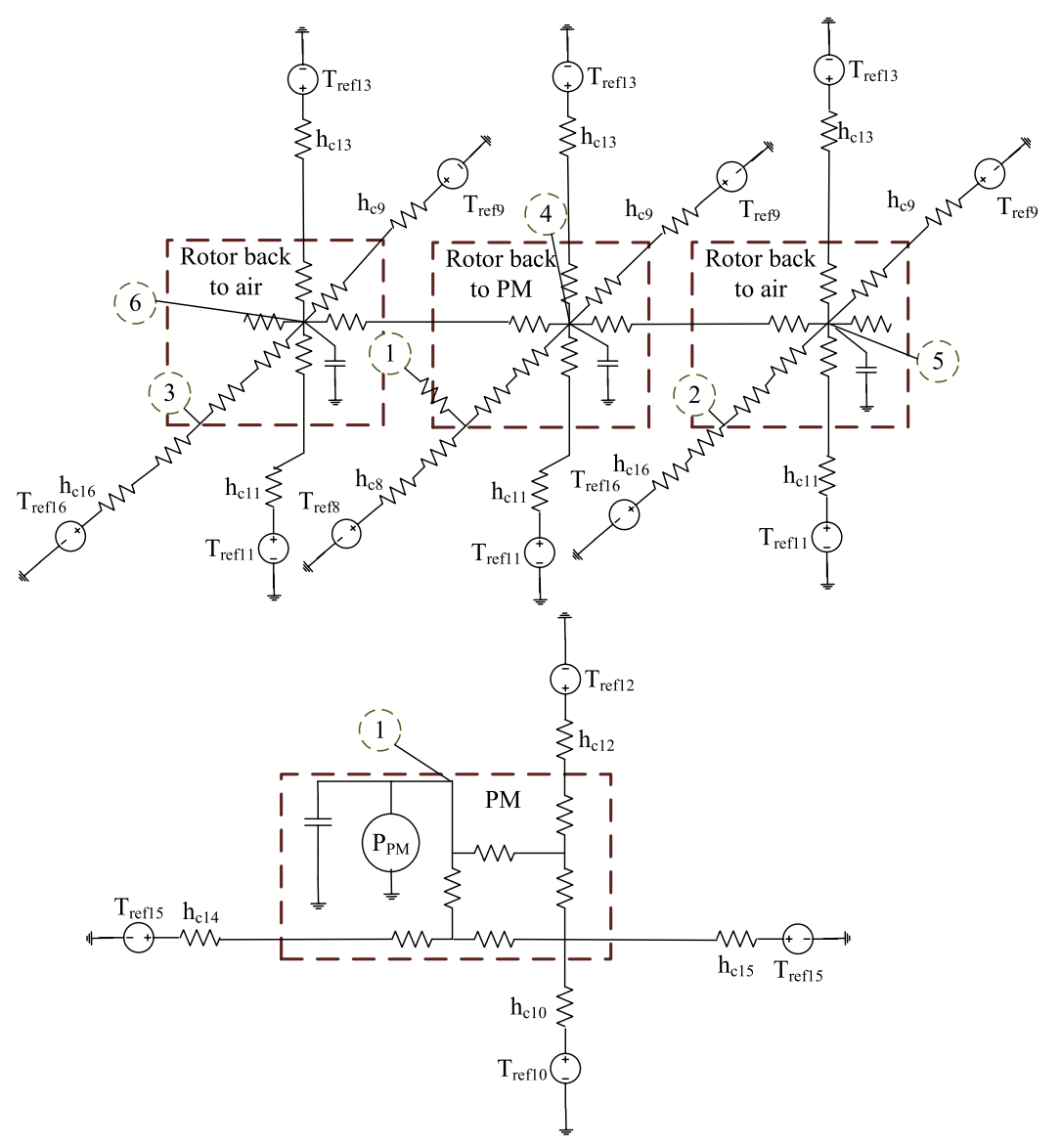

Figure 3. LPTN of the rotor. 


\subsection{D Thermal FEM Model}

A 3D FEM model is developed to verify the results of the coupled electromagnetic-thermal analytical models based studies in the next sections. The modeled quarter tooth and rotor segment are shown in Figure 4a,b, respectively.

The boundary conditions used in the simulation are thermal insulation for parts parallel to the cutting plane and convective heat transfer for convected surfaces. The power losses of the different machine parts are assumed to be equally distributed on the volume.

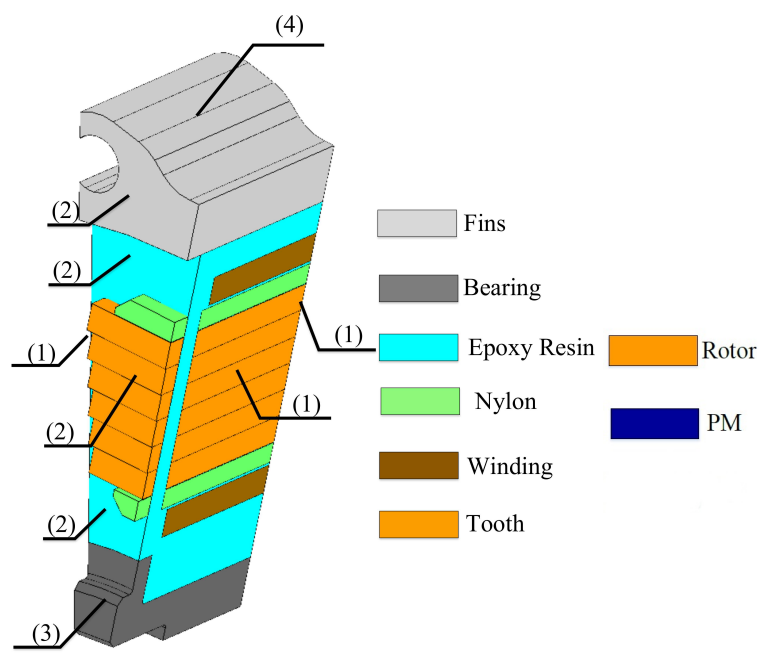

(a)

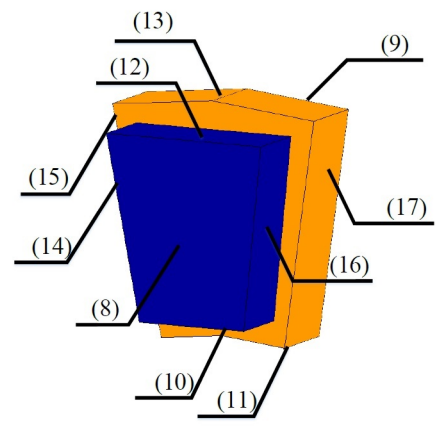

(b)

Figure 4. Machine Modeled parts (a) Stator modeled part: (1) thermal insulation; (2) stator facing rotor upper part; (3) stator facing rotor lower part; (4) stator side wall. (b) Rotor modeled part: (8) rotor facing stator upper; (9) rotor left side; (10) PM lower; (11) rotor lower; (12) PM upper; (13) rotor upper; (14) PM left; (15) PM right; (16) rotor facing stator.

\section{Coupled EM-Thermal Study}

Both the electromagnetic and the thermal models are needed in this study to compute the losses from the electromagnetic models and the temperatures from the thermal model resulting from variation of the studied parameters. These models are coupled by the dependence of the winding resistivity on the temperature. The winding resistivity change is handled by solving the coupled models iteratively until stabilization of the temperature as in the flow chart in Figure 5. 


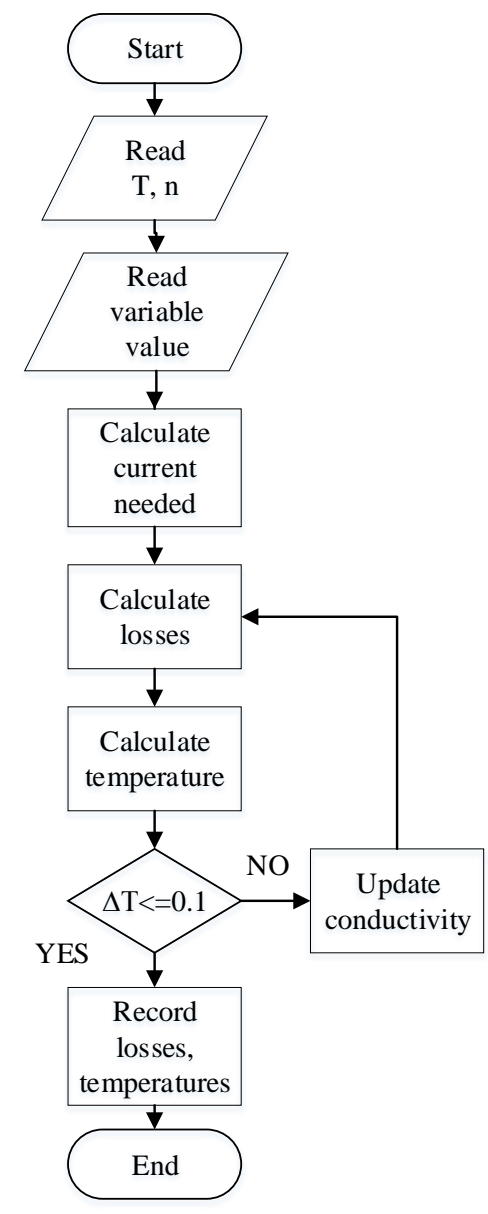

Figure 5. The calculations flow chart.

\section{The Parametric Studies}

In this section, the resultant power losses, efficiency and the average steady state temperature variation of the winding, the core and the PMs with the air gap length, the speed, the inward heat extraction fins thickness and the PM thickness are studied. These studies are done on a $4 \mathrm{~kW}, 2500 \mathrm{rpm}$ YASA machine with the geometrical parameters in Table 2.

Table 2. YASA geometrical parameters.

\begin{tabular}{ccc}
\hline Parameter & Value & Unit \\
\hline number of poles & 16 & - \\
teeth number & 15 & - \\
outer diameter housing & 195 & $\mathrm{~mm}$ \\
outer diameter active & 148 & $\mathrm{~mm}$ \\
PM thickness & 4 & $\mathrm{~mm}$ \\
rotor outer radius & 74 & $\mathrm{~mm}$ \\
slot width & 11 & $\mathrm{~mm}$ \\
\hline
\end{tabular}

\subsection{Air Gap Length Study}

The study is done for air gap lengths ranging from 0.6 to $5 \mathrm{~mm}$ with the power and the speed fixed at $4 \mathrm{~kW}$ and $2500 \mathrm{rpm}$. As the air gap length increases and as the air gap flux decreases, the current needed to provide the same output torque should also increase. 
The winding losses keep increasing quadratically with the air gap length as shown in Figure 6 as a result of the increasing stator current. On the other hand, the iron losses have a minimum value at $3.5 \mathrm{~mm}$ air gap length. This can be explained as follows: as the air gap length increases, this results in decreasing the air gap flux density component generated by the PMs and increasing the armature reaction due to increased stator current. The rate of change of the overall flux density reaches a minimum at $3.5 \mathrm{~mm}$ air gap length resulting in minimum core losses at this value.

The PM losses keep decreasing with the air gap length as in Figure 7.

From Figure 6, it is clear that the total losses keep increasing with the air gap length and hence, from Figure 8, the efficiency keeps decreasing from $96 \%$ at $1 \mathrm{~mm}$ to $84 \%$ at $5 \mathrm{~mm}$.

Whether the steady-state temperature will increase or decrease with the air gap length depends not only on the losses but also on the change of the air gap convection coefficient. From Figure 9, it is seen that the air gap convection coefficient reduces with the air gap length. This explains the continuous increase in the winding and the core temperature with the air gap length as shown in Figure 10.

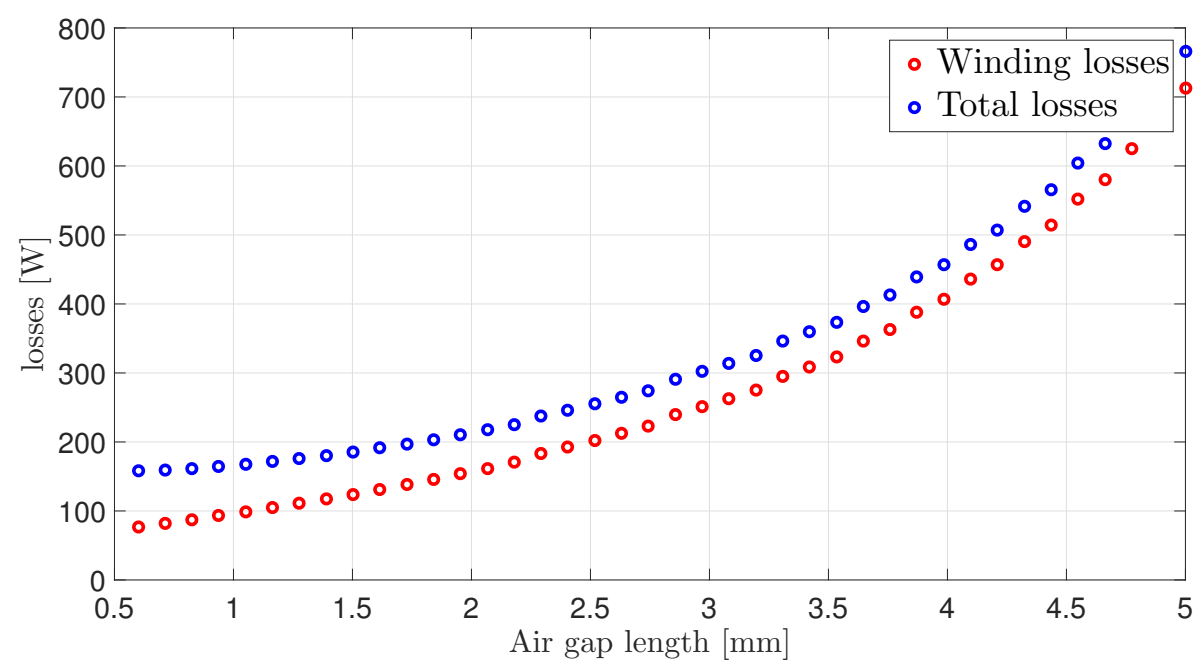

Figure 6. The winding and the total losses variation with the air gap length.

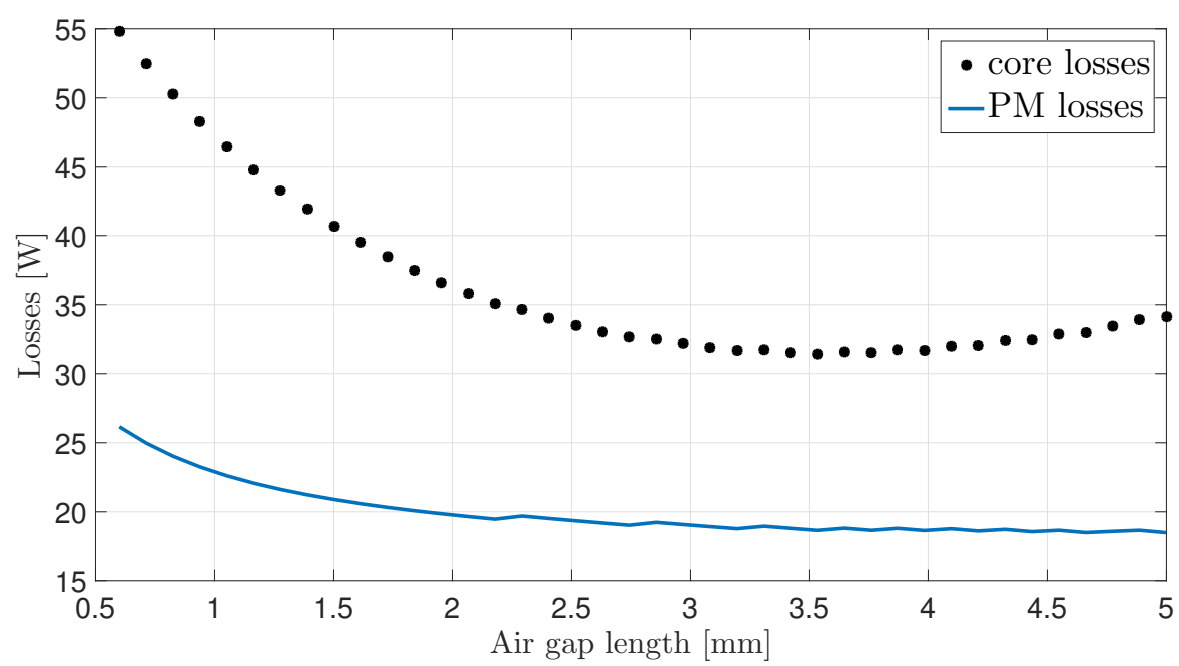

Figure 7. The core and the PM losses variation with the air gap length. 


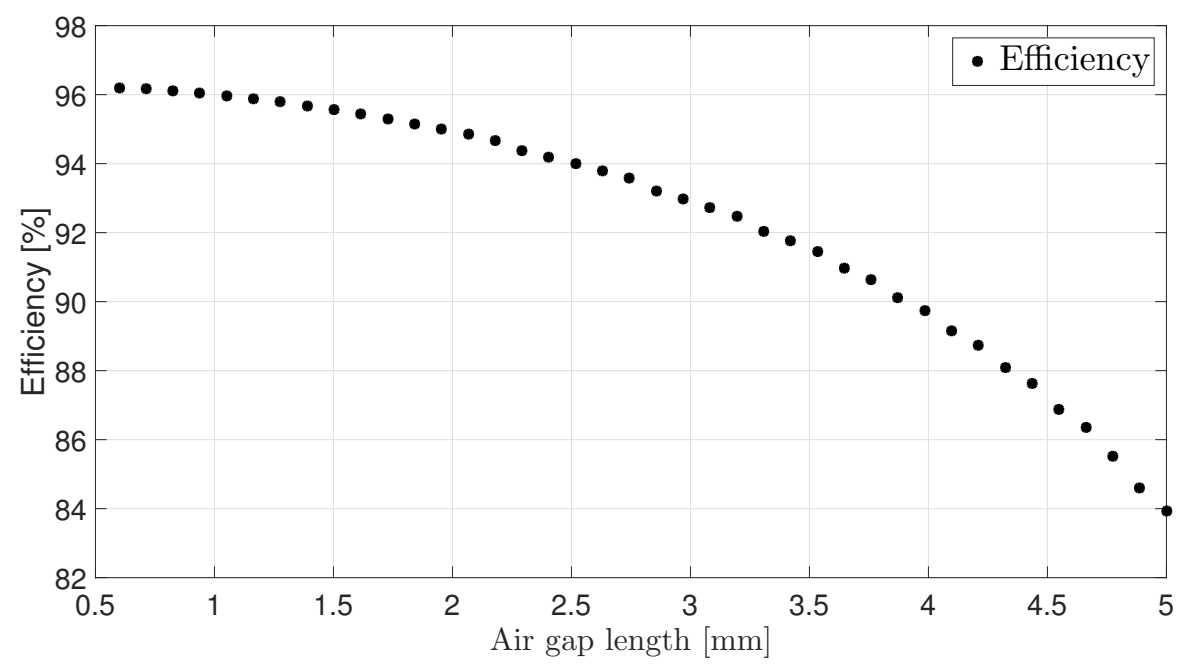

Figure 8. The efficiency variation with the air gap length.

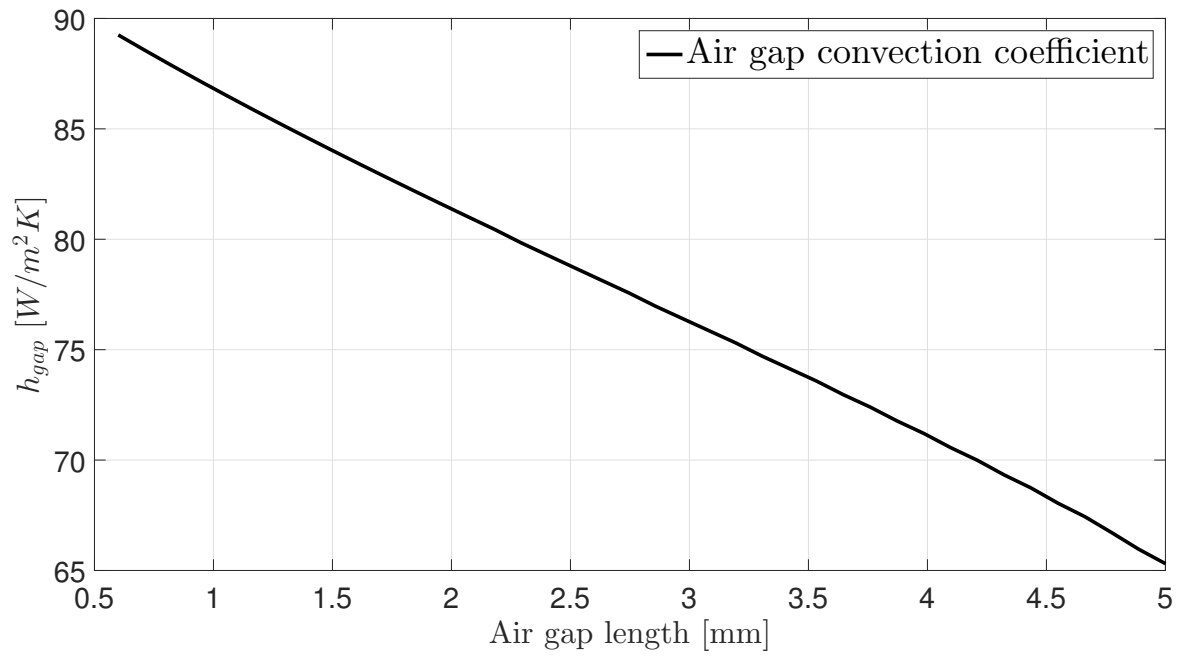

Figure 9. The air gap convection coefficient variation with the air gap length.

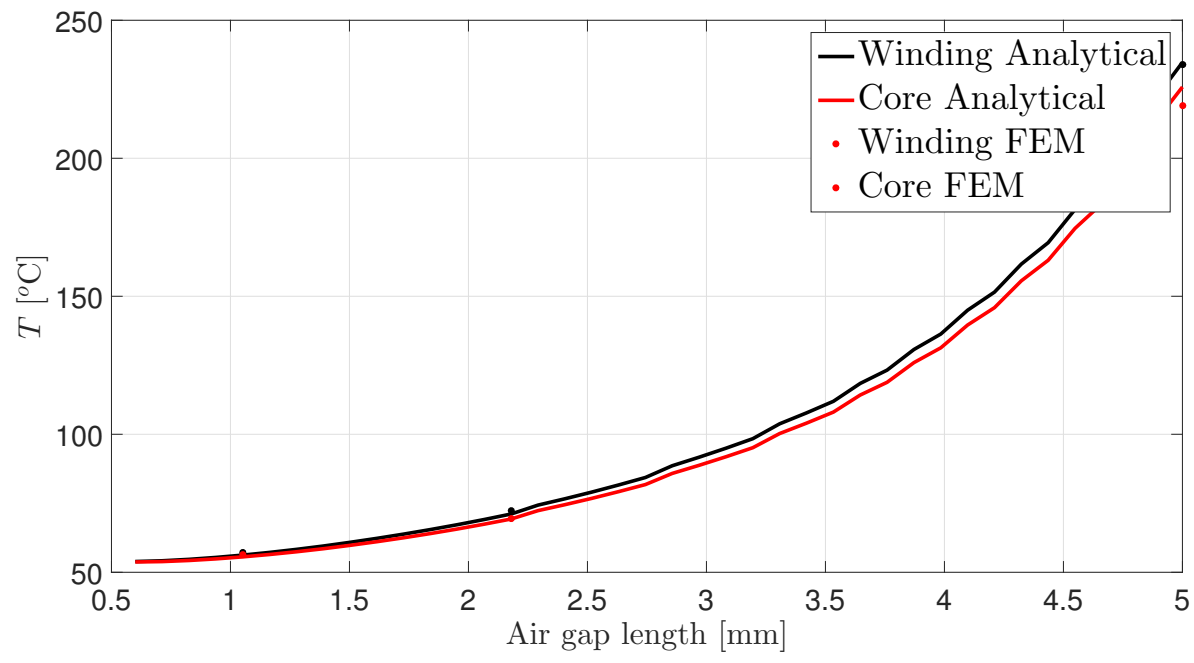

Figure 10. The winding and the core temperature variation with the air gap length. 
From Figure 11, the PM temperature has its minimum value at $2.7 \mathrm{~mm}$ air gap length. This can be explained by investigating Figures 7 and 9. The PM losses keep decreasing which means less heat generation and also the convection coefficient keeps decreasing, which means less heat evacuation. For air gaps less than $2.7 \mathrm{~mm}$, the rate by which the heat generation decreases is higher than the rate of decrease of the convection coefficient and the opposite happens at values higher than $2.7 \mathrm{~mm}$.

It can also be seen that the good correspondence between the FEM results and the analytical method and the small effect of the air gap length value on the temperature of the PMs.

Based on the above presented air gap variation effects on the losses and the temperature, it is recommended to keep the air gap length as low as possible to get high operating efficiency and low temperature stresses.

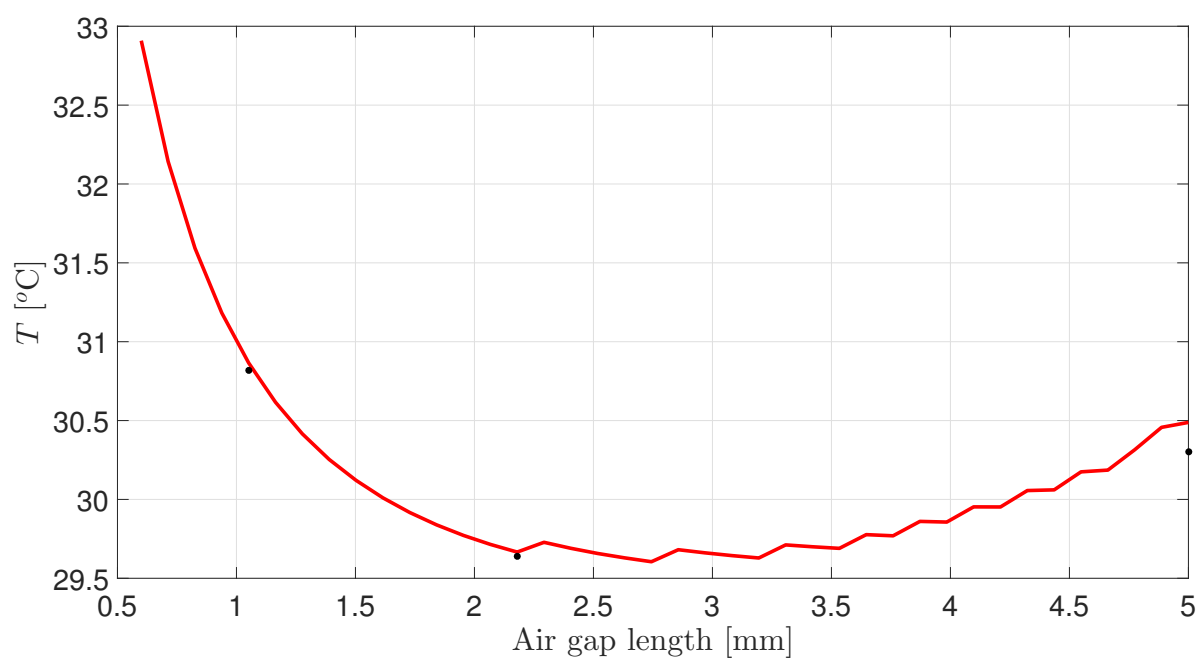

Figure 11. The PM temperature variation with the air gap length.

\subsection{Variable Speed Study}

This study is done for speed range from 120 to $2500 \mathrm{rpm}$ at air gap length $1 \mathrm{~mm}$ and output torque fixed at $18.7 \mathrm{~N} . \mathrm{m}$, which is the rated torque of the $4 \mathrm{~kW}$ machine. Variable speed operation in synchronous machines requires variable supply frequency. As the supply frequency increases, the speed also increases and this results in two effects with counter actions on the machine temperature. On the one hand, the frequency increase causes an increase in all loss components in the machine, which results in higher heat generation. On the other hand, the speed increase results in higher air gap convection coefficients, which results in better heat evacuation. These counter actions make it necessary to investigate the machine temperature at different speeds to identify the safe operating speed range. From Figure 12, it can be seen that the PMs and core losses keep increasing with the speed, which is expected from Equation (1). On the other hand, the winding losses decrease in the speed range from 120 to $489 \mathrm{rpm}$. 


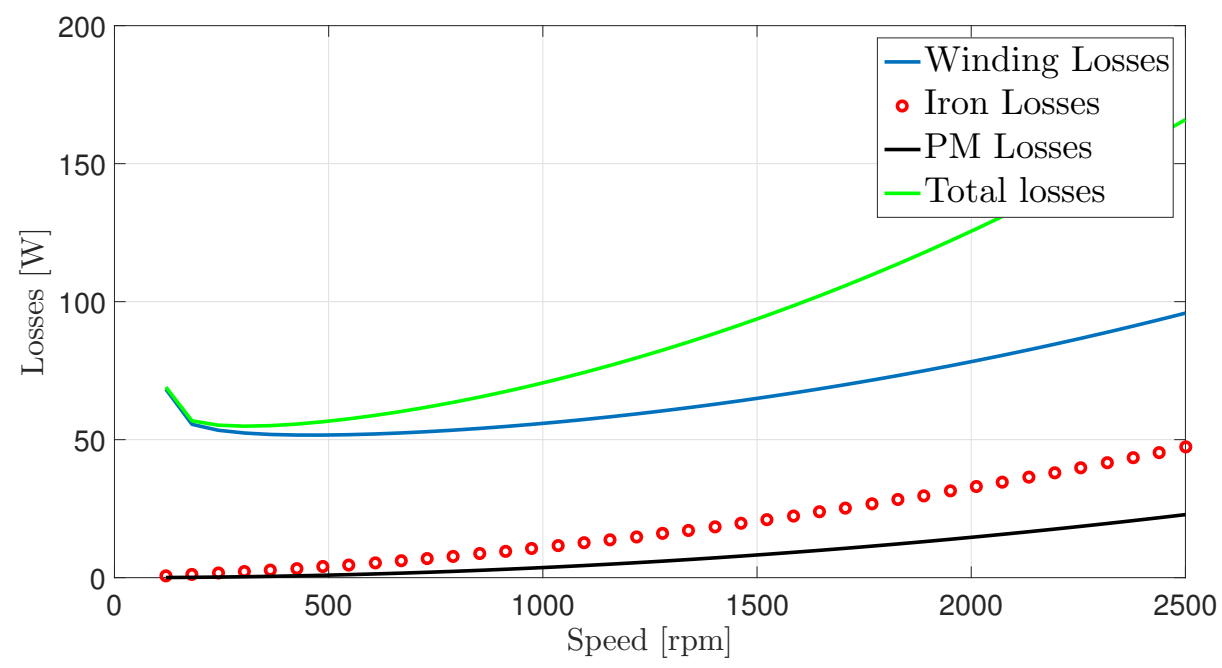

Figure 12. The winding, core, PMs and total loss variation with the speed.

This can be explained as follows in the low speed operation, the skin and proximity effects have a little effect on the winding resistance while, by inspecting Figure 13, the winding temperature keeps decreasing with speed up to $1218 \mathrm{rpm}$, which results in decreasing winding resistance and hence decreasing winding losses.

More investigations in Figures 12 and 13 reveal that there are three regions: the first one up to speed of $486.2 \mathrm{rpm}$ and explained above; the second one, from 486.2 to $1218 \mathrm{rpm}$ the winding temperature still decreasing in this speed range, but the winding losses increase, which means that the skin and proximity effect became significant and resulted in an increase in the winding resistance rather than decreasing with the decreasing temperature. In the last region, the skin, the proximity and the temperature are all increasing, resulting in an increase in the winding resistance and hence the winding losses.

The efficiency variation with the speed is shown in Figure 14.

The PM temperature in Figure 15 has a minimum at a speed $1035 \mathrm{rpm}$. In the speed region below the minimum, the temperature keeps decreasing, which means that the increase in the magnet losses is lower than the increase in the convection coefficients.

It is also informative to see from Figure 16 the values of the convection coefficients at each speed value.

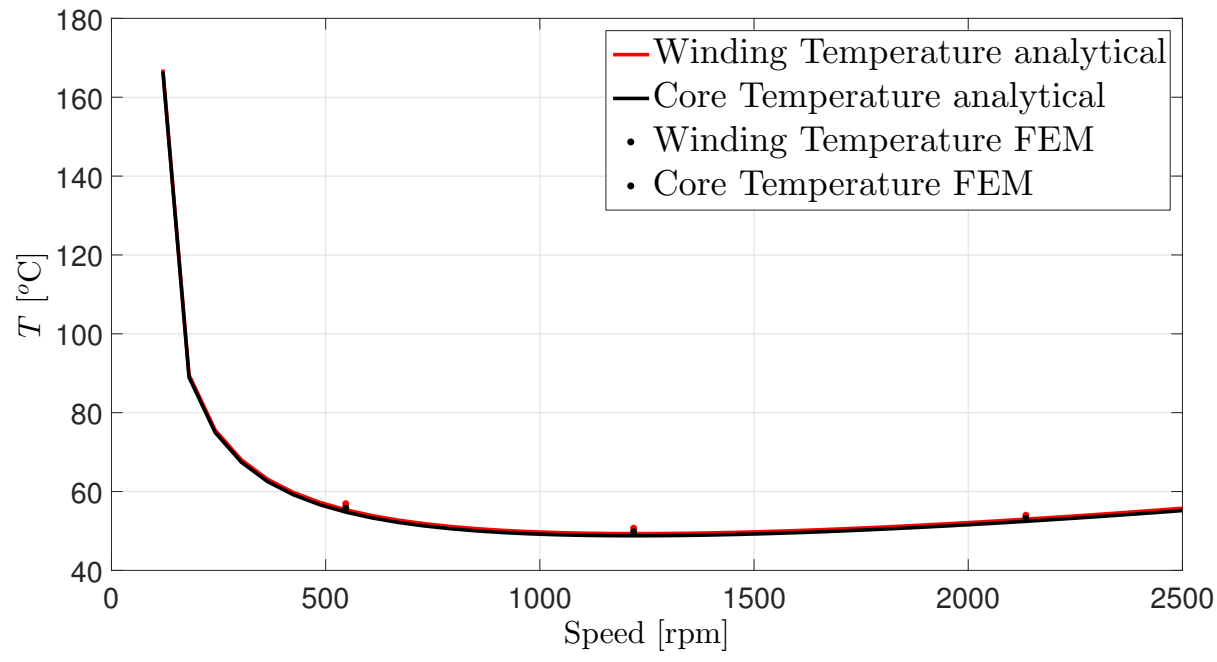

Figure 13. The winding and the core temperature variation with the speed. 


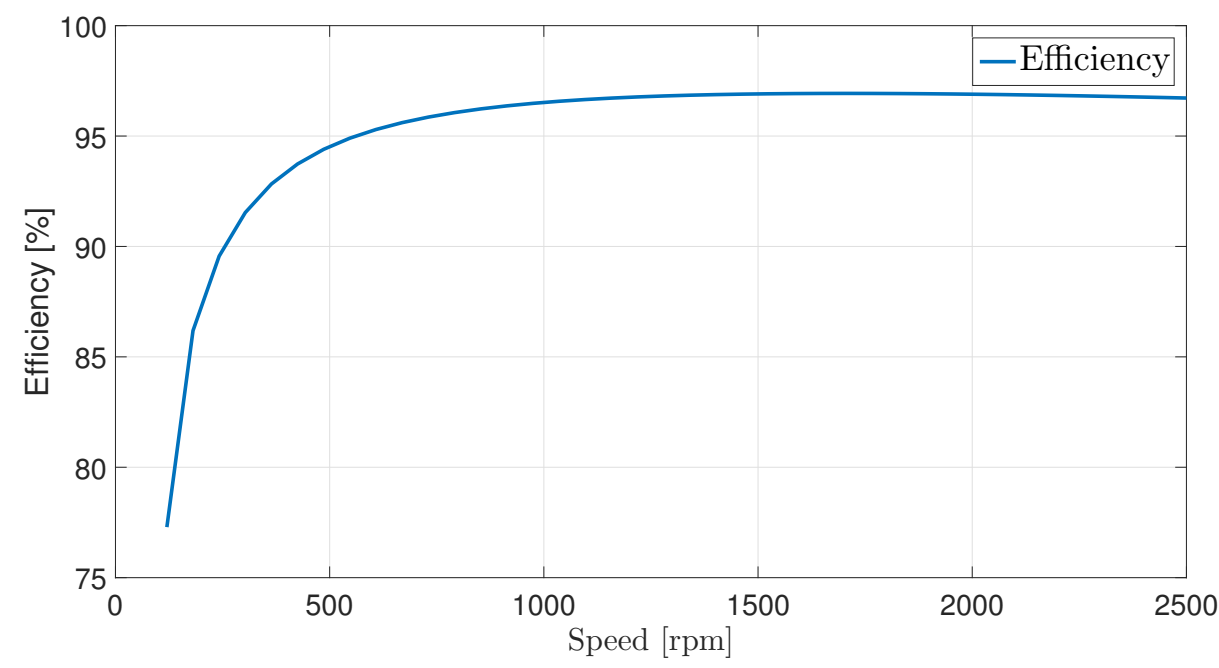

Figure 14. The efficiency variation with the speed.

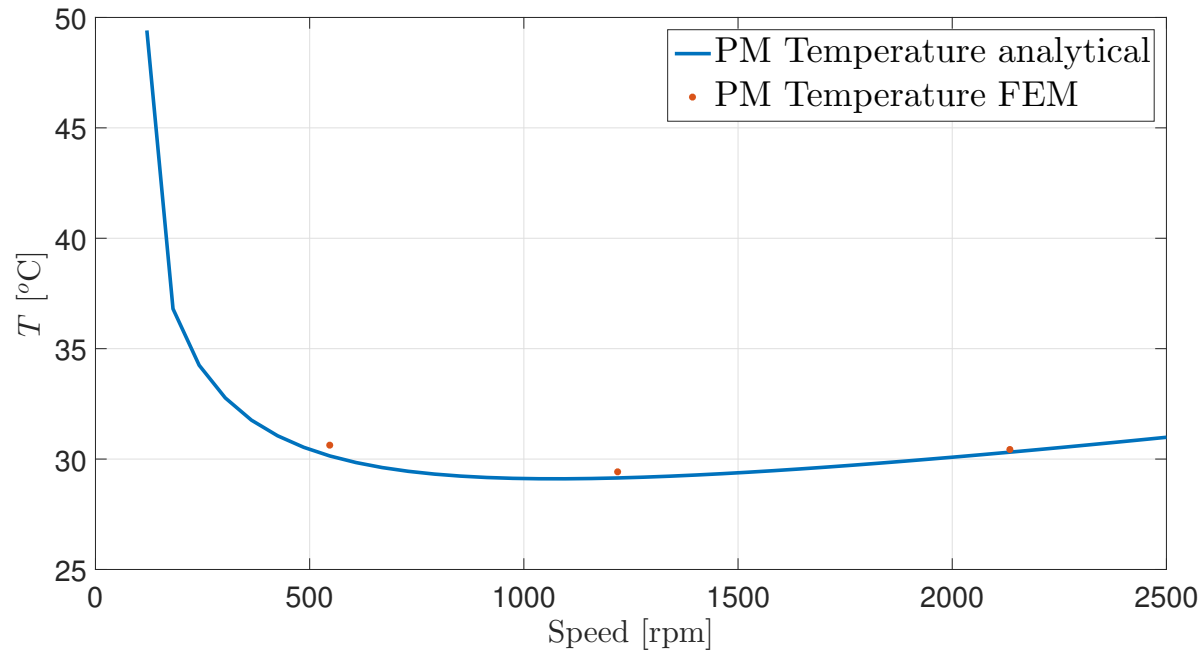

Figure 15. The PM temperature variation with the speed.

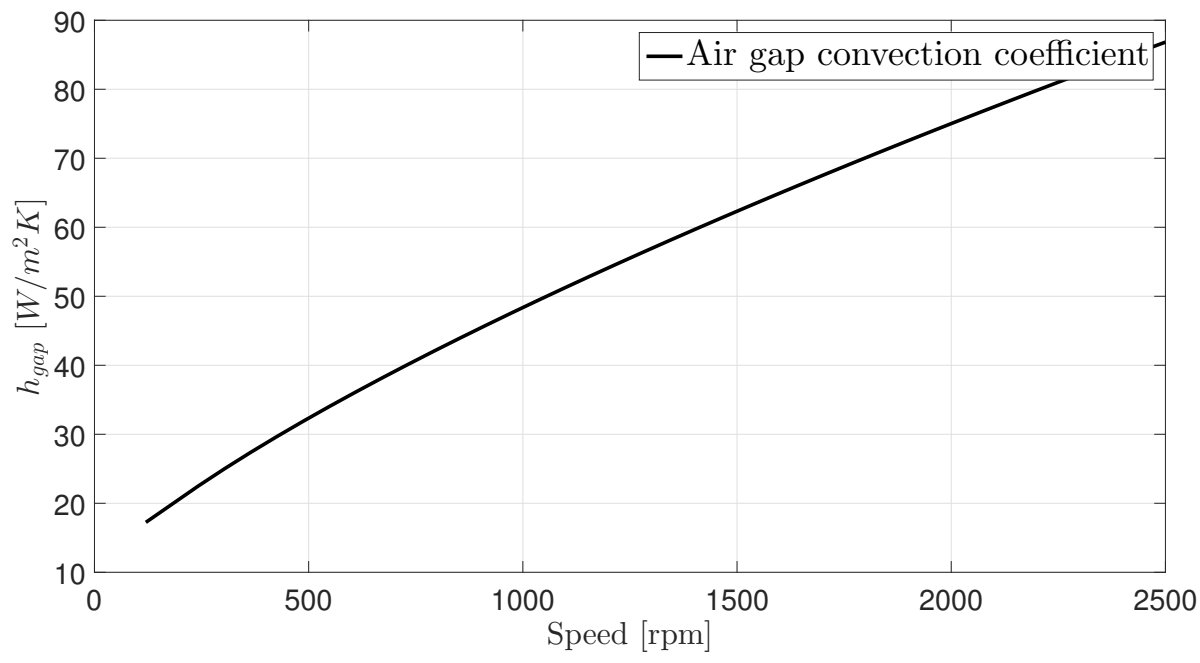

Figure 16. The air gap convection coefficient variation with the speed. 


\subsection{Inward Heat Extraction Fins Thickness Study}

This study is done for fins thickness in the range from 0 to $6 \mathrm{~mm}$ at $4 \mathrm{~kW}$ and $2500 \mathrm{rpm}$. An inward heat extraction fins of aluminum are put between the windings to enhance the heat evacuation from the windings. Figure 17 illustrates the heat extraction fins extending along the axial length of the effective winding.

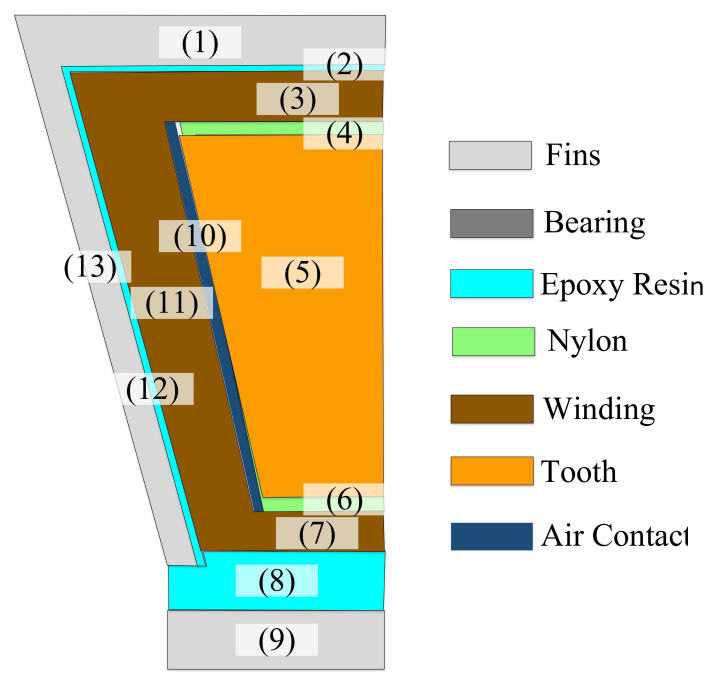

Figure 17. A quarter tooth part illustrating the inward heat extraction fins.

As the thickness of the inward heat extraction fins increases, its thermal resistance in the axial direction decreases. This leads to a better heat evacuation. At the same time, the slot area available for the windings will decrease, causing a lower winding factor and hence higher winding resistance and losses. Thus, the fins thickness should be selected carefully. Figure 18 shows the different losses variation with the fin thickness along with the total losses. The winding losses are minimum at $0.6 \mathrm{~mm}$. This can be explained by inspecting Figure 19: the winding temperature decreases up to a thickness of $1.4 \mathrm{~mm}$, which contributes to the reduction of the winding resistance and hence the winding losses. In addition, by inspecting Figure 19, the optimum fins thickness is $1.4 \mathrm{~mm}$ as the temperature reduces by $8{ }^{\circ} \mathrm{C}$ compared to the case without inward heat extraction fins.

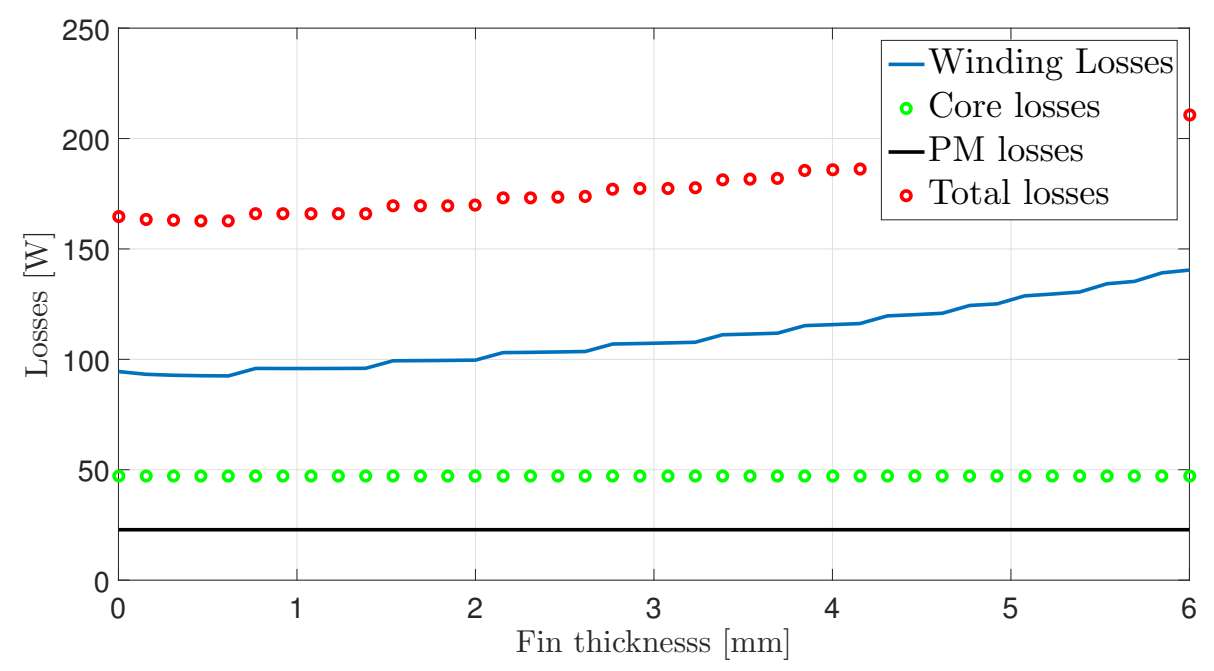

Figure 18. The losses variation with the fins thickness. 


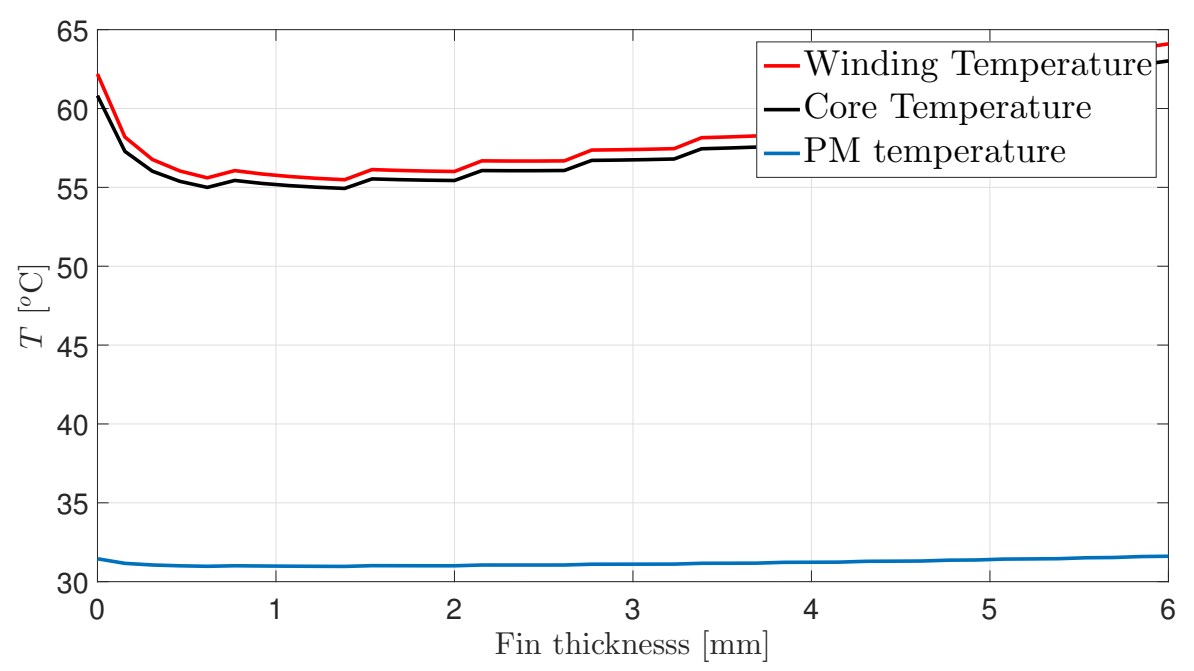

Figure 19. The winding, the core and the PM temperature variation with the fins thickness.

Figure 20 shows the efficiency variation with the fins thickness. It reduces from $96.1 \%$ in the case without fins to $95 \%$ at $5 \mathrm{~mm}$ thickness. The efficiency doesn't decrease too much at the optimal fin thickness of $1.4 \mathrm{~mm}$.

The conclusion is that the coolest machine is obtained at $1.4 \mathrm{~mm}$ thickness while the most efficient machine is obtained at $0.6 \mathrm{~mm}$.

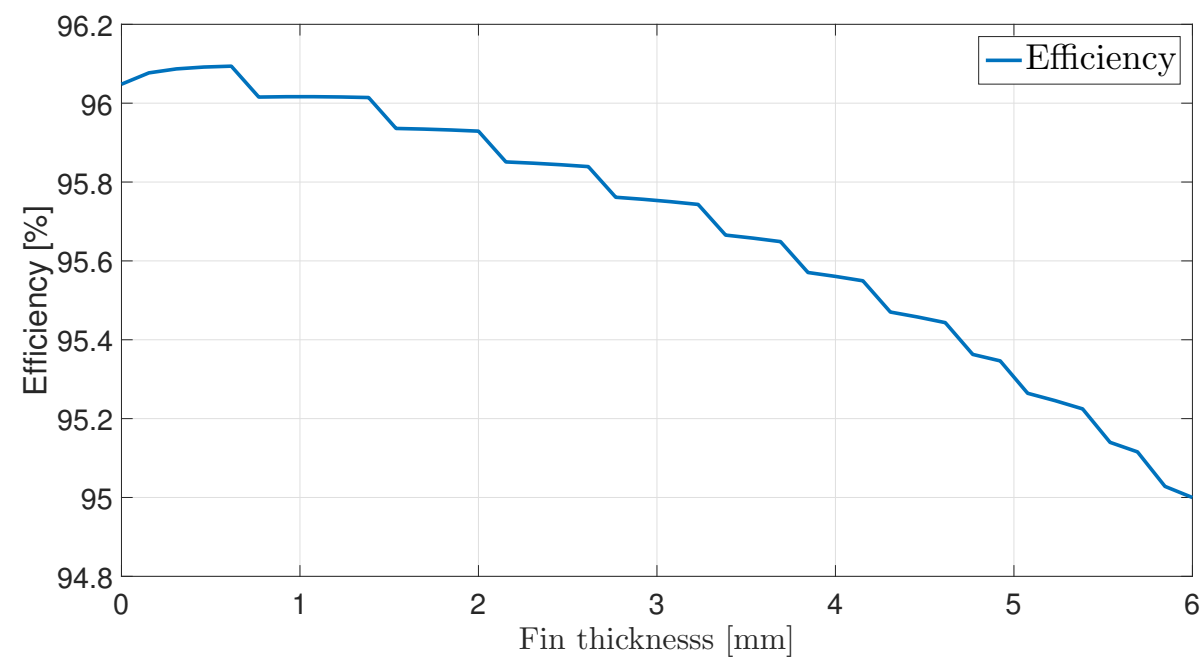

Figure 20. The efficiency variation with the fins thickness.

\subsection{PM Thickness Study}

This study is done at a magnet thickness range from 1 to $6 \mathrm{~mm}$ at a $4 \mathrm{~kW}$ and $2500 \mathrm{rpm}$. The PM thickness is one of the important parameters affecting the overall flux density in the machine and hence the losses and, at the same time, affects the air gap convection coefficient (3).

Figure 21 shows the losses variation with the magnet thickness. The copper losses keep decreasing with the magnet losses as expected, due to the decrease in the required current for getting the rated output torque at each magnet thickness. The PM losses are also decreasing with the magnet thickness. This is due to the reduction occurring in the stator current and the armature reaction. Hence, the induced voltage in the PMs will decrease, leading to a decreased PM loss.

The core losses have a minimum value at $1.6 \mathrm{~mm}$ magnet thickness. This can be explained by the different rate of the rise of the PM flux density and rate of decrease of the armature reaction with the 
PM thickness. At $1.6 \mathrm{~mm}$ thickness, the rate of change of the total air gap flux density hits a minimum, resulting in minimum losses.

From Figure 22, the efficiency keeps increasing with the magnet thickness.

The temperature of the three parts keeps decreasing with the magnet thickness as shown in Figure 23, which is expected from the decreasing losses.

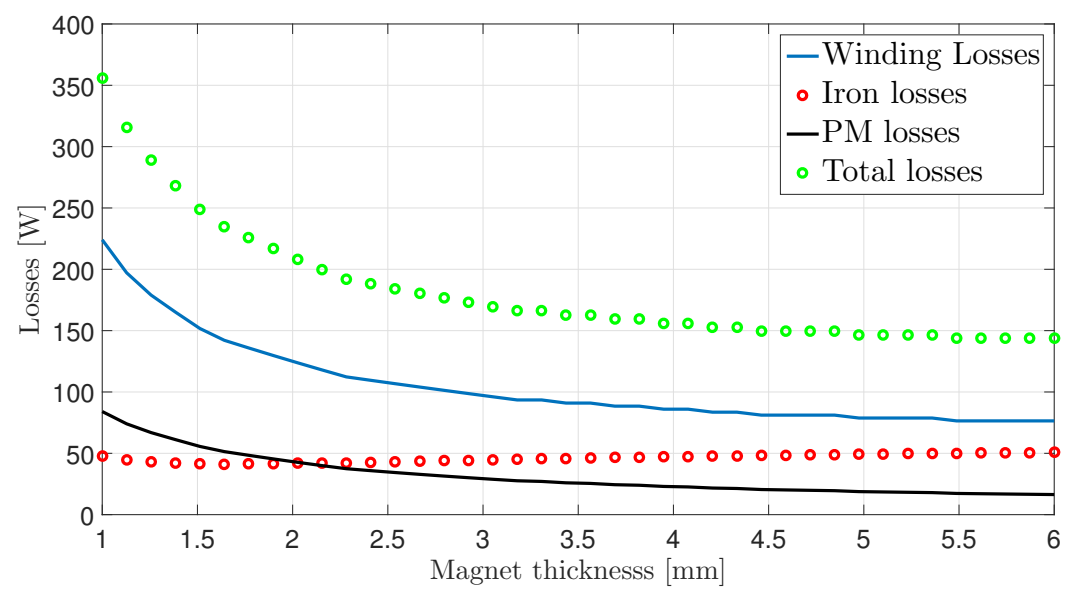

Figure 21. The losses variation with the magnet thickness.

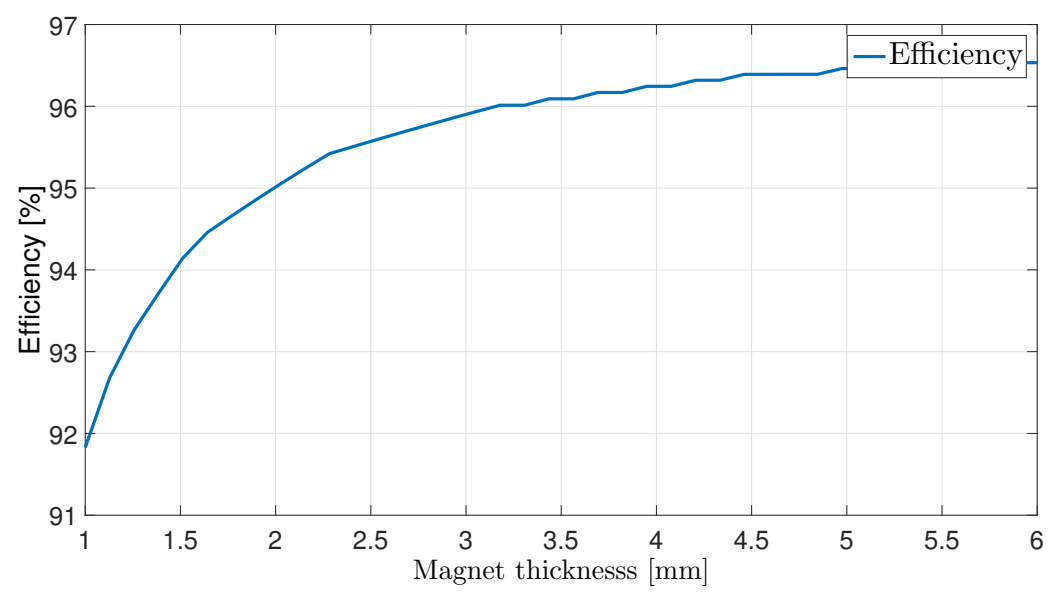

Figure 22. The efficiency variation with the magnet thickness.

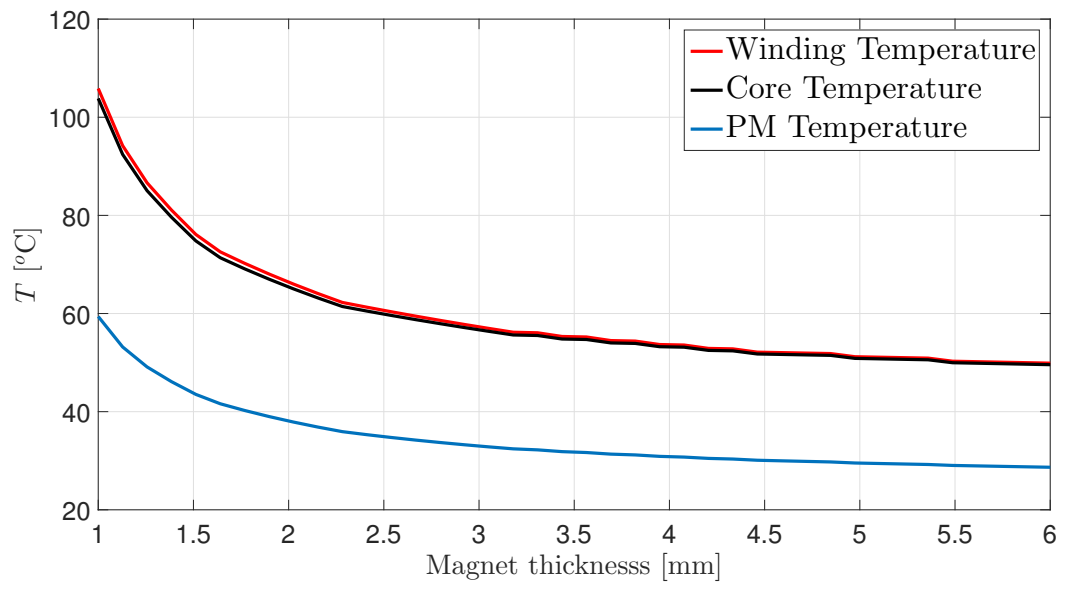

Figure 23. The temperature variation with the magnet thickness. 


\section{Experimental Validation}

The validation measurements are carried out using the setup shown in Figure 24. It consists of a YASA axial flux permanent magnet synchronous machine of $4 \mathrm{~kW}$ and $2500 \mathrm{rpm}$ rated values coupled to an induction machine of $7.5 \mathrm{~kW}$ and $3000 \mathrm{rpm}$ rated values driven by a commercial drive. For torque measurements, a torque sensor is installed. The winding and the core temperatures are measured by an embedded resistance temperature detector (PT100) sensor, while the PM temperature is measured by an infrared temperature sensor (ZTP-135SR).

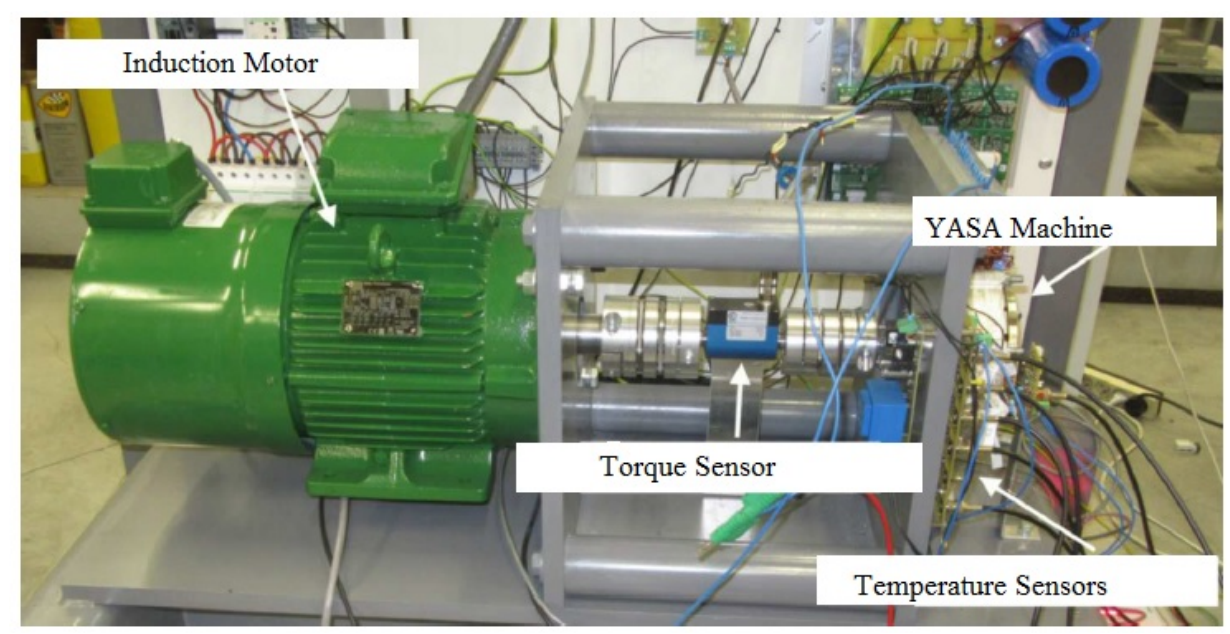

Figure 24. The experimental setup.

In addition, a dspace 1104 platform is used to send the speed setpoint command to the induction motor commercial drive.

To be able to precisely validate the model, all sources of uncertainties in the machine should be eliminated. To do that, the real magnets are replaced by dummy aluminum parts with the same shape and dimensions to eliminate the magnets losses. In addition, to eliminate the core losses, a DC current is injected in the stator rather than an AC one. By this method, the winding losses and the rotational losses are the only loss components remaining.

The air gap is set to $1 \mathrm{~mm}$, the fins thickness is set to $1 \mathrm{~mm}$ and the induction motor is operated at $1000 \mathrm{rpm}$ and a DC current is injected in the stator winding to get a $100 \mathrm{~W}$ winding losses. The temperature sensors are sampled and recorded every $5 \mathrm{~s}$ for $110 \mathrm{~min}$. This experiment is repeated at $2000 \mathrm{rpm}$. After every experiment, the machine is completely cooled to the ambient temperature. Tables 3 and 4 are showing the winding and the PM steady state temperature at each speed value, the analytical and FEM models, and the experimental setup.

The results show a good correspondence between the models and the experimental work.

Table 3. Winding temperature validation.

\begin{tabular}{cccc}
\hline Speed (rpm) & Analytical $\left({ }^{\circ} \mathbf{C}\right)$ & FEM $\left({ }^{\circ} \mathbf{C}\right)$ & Experimental $\left({ }^{\circ} \mathbf{C}\right)$ \\
\hline 1000 & 61.73 & 63.89 & 62.74 \\
2000 & 49.03 & 50.13 & 51.43 \\
\hline
\end{tabular}

Table 4. PM temperature validation.

\begin{tabular}{lccr}
\hline Speed (rpm) & Analytical $\left({ }^{\circ} \mathbf{C}\right)$ & FEM $\left({ }^{\circ} \mathbf{C}\right)$ & Experimental $\left({ }^{\circ} \mathbf{C}\right)$ \\
\hline 1000 & 29.44 & 29.93 & 30.52 \\
2000 & 26.89 & 27.05 & 28.12 \\
\hline
\end{tabular}




\section{Conclusions}

In this paper, the effect of the air gap length, the speed, the inward heat extraction fins thickness and the PM thickness on the different power losses and the temperature of the different components are studied at the rated load condition. The skin and proximity effects are taken into account and the temperature dependent electrical conductivities are also taken into account in these coupled electromagnetic-thermal studies. The results reveal that the winding and core temperature are much more sensitive to the changes in the air gap length, the speed and the inward heat extraction fins than the PM temperature. In all these studies, the temperature variation with the variable under study can be divided into regions. In every region, one of the factors affecting the increase or the decrease in the temperature dominates over the others. Based on these studies, the recommended air gap range is determined, the safe operating speed range is identified and the optimum inward heat extraction fins thickness is revealed.

Author Contributions: Each of the authors contributed to the preparation of this research paper. A.H.M. made the coupled parametric studies and wrote the paper. A.H. developed the electromagnetic model. H.V. revised the paper. P.S. revised the manuscript substantially.

Funding: This research received no external funding.

Acknowledgments: This research was done in the framework of the Hipercool project from Flanders Make.

Conflicts of Interest: The authors declare no conflict of interest.

\section{References}

1. Giulii Capponi, F.; De Donato, G.; Caricchi, F. Recent advances in axial-flux permanent-magnet machine technology. IEEE Trans. Ind. Appl. 2012, 48, 2190-2205. [CrossRef]

2. Hemeida, A.; Sergeant, P. Analytical modeling of surface PMSM using a combined solution of Maxwell's equations and Magnetic Equivalent Circuit (MEC). IEEE Trans. Magn. 2014, 50, 7027913. [CrossRef]

3. Woolmer, T.J.; McCulloch, M.D. Analysis of the yokeless and segmented armature machine. In Proceedings of the IEEE International Electric Machines and Drives Conference, IEMDC 2007, Antalya, Turkey, 3-5 May 2007; Volume 1, pp. 704-708.

4. Letelier, A.B.; González, D.A.; Tapia, J.J.A.; Wallace, R.; Valenzuela, M.A. Cogging torque reduction in an axial flux PM machine via stator slot displacement and skewing. IEEE Trans. Ind. Appl. 2007, 43, 685-693. [CrossRef]

5. Wang, Z.; Masaki, R.; Morinaga, S.; Enomoto, Y.; Itabashi, H.; Ito, M.; Tanigawa, S. Development of an axial gap motor with amorphous metal cores. IEEE Trans. Ind. Appl. 2011, 47, 1293-1299. [CrossRef]

6. Hemeida, A.; Sergeant, P.; Vansompel, H. Comparison of Methods for Permanent Magnet Eddy Current Loss Computations With and Without Reaction Field Considerations in Axial Flux PMSM. IEEE Trans. Magn. 2015, 9464, 1-11. [CrossRef]

7. Hsieh, M.F.; Hsu, Y.C. A Generalized Magnetic Circuit Modeling Approach for Design of Surface Permanent-Magnet Machines. IEEE Trans. Ind. Electron. 2012, 59, 779-792. [CrossRef]

8. Kano, Y.; Kosaka, T.; Matsui, N. A simple nonlinear magnetic analysis for axial-flux permanent-magnet machines. IEEE Trans. Ind. Electron. 2010, 57, 2124-2133. [CrossRef]

9. Tangudu, J.; Jahns, T.; EL-Refaie, A.; Zhu, Z. Lumped parameter magnetic circuit model for fractional-slot concentrated-winding interior permanent magnet machines. In Proceedings of the 2009 IEEE Energy Conversion Congress and Exposition, San Jose, CA, USA, 20-24 September 2009; pp. 2423-2430.

10. Tan, Z.; Song, X.G.; Ji, B.; Liu, Z.; Ma, J.E.; Cao, W.P. 3D thermal analysis of a permanent magnet motor with cooling fans. J. Zhejiang Univ. Sci. A 2015, 16, 616-621. [CrossRef]

11. Polikarpova, M.; Ponomarev, P.; Lindh, P.; Petrov, I.; Jara, W.; Naumanen, V.; Tapia, J.A.; Pyrhonen, J. Hybrid Cooling Method of Axial-Flux Permanent-Magnet Machines for Vehicle Applications. IEEE Trans. Ind. Electron. 2015, 62, 7382-7390. [CrossRef]

12. Marignetti, F.; Delli Colli, V.; Coia, Y. Design of Axial Flux PM Synchronous Machines Through 3-D Coupled Electromagnetic Thermal and Fluid-Dynamical Finite-Element Analysis. IEEE Trans. Ind. Electron. 2008, 55, 3591-3601. [CrossRef] 
13. Marignetti, F.; Colli, V. Thermal Analysis of an Axial Flux Permanent-Magnet Synchronous Machine. IEEE Trans. Magn. 2009, 45, 2970-2975. [CrossRef]

14. Rostami, N.; Feyzi, M.R.; Pyrhonen, J.; Parviainen, A.; Niemela, M. Lumped-Parameter Thermal Model for Axial Flux Permanent Magnet Machines. IEEE Trans. Magn. 2013, 49, 1178-1184. [CrossRef]

15. Lim, C.; Bumby, J.; Dominy, R.; Ingram, G.; Mahkamov, K.; Brown, N.; Mebarki, A.; Shanel, M. 2-D lumped-parameter thermal modelling of axial flux permanent magnet generators. In Proceedings of the 2008 18th International Conference on Electrical Machines, Vilamoura, Portugal, 6-9 September 2008; pp. 1-6.

16. Mohamed, A.H.; Hemeida, A.; Rashekh, A.; Vansompel, H.; Arkkio, A.; Sergeant, P. A 3D Dynamic Lumped Parameter Thermal Network of Air-Cooled YASA Axial Flux Permanent Magnet Synchronous Machine. Energies 2018, 11, 774. [CrossRef]

17. Jiang, W.; Member, S.; Jahns, T.M. Coupled Electromagnetic-Thermal Analysis of Electric Machines Including Transient Operation Based on Finite-Element Techniques. IEEE Trans. Ind. Appl. 2015, 51, 1880-1889. [CrossRef]

18. Bertotti, G. General Properties of Power Losses in Soft Ferromagnetic Materials. IEEE Trans. Magn. 1987, 24, 621-630. [CrossRef]

19. Vansompel, H. Design of an Energy Efficient Axial Flux Permanent Magnet Machine. Ph.D. thesis, Ghent University, Ghent, Belgium, 2013.

20. Rasekh, A.; Sergeant, P.; Vierendeels, J. Convective heat transfer prediction in disk-type electrical machines. Appl. Therm. Eng. 2015, 91, 778-790. [CrossRef]

21. Rasekh, A.; Sergeant, P.; Vierendeels, J. Fully predictive heat transfer coefficient modeling of an axial flux permanent magnet synchronous machine with geometrical parameters of the magnets. Appl. Therm. Eng. 2017, 110, 1343-1357. [CrossRef]

(C) 2018 by the authors. Licensee MDPI, Basel, Switzerland. This article is an open access article distributed under the terms and conditions of the Creative Commons Attribution (CC BY) license (http://creativecommons.org/licenses/by/4.0/). 